\title{
AC Brushless Drive With Low-Resolution Hall-Effect Sensors for Surface-Mounted PM Machines
}

\author{
Fabio Giulii Capponi, Member, IEEE, Giulio De Donato, Student Member, IEEE, Luca Del Ferraro, Member, IEEE, \\ Onorato Honorati, Member, IEEE, Michael C. Harke, Student Member, IEEE, and Robert D. Lorenz, Fellow, IEEE
}

\begin{abstract}
An ac brushless drive in which Hall-effect sensors are used as rotor position sensors is presented in this paper. Three different methods to obtain a high-resolution position estimation from the low-resolution sensors are described and compared through simulation and experimental testing. The proposed control algorithm's most innovative feature is its adaptability to the entire speed range, including startup, when using any of the three estimation algorithms. The control algorithm has been implemented and tested in order to drive a slotless axialflux permanent-magnet (PM) machine for domestic appliance applications.
\end{abstract}

Index Terms-Low-resolution sensors, position and velocity estimation, surface-mounted permanent-magnet (PM) machine, vector-tracking observer.

\section{INTRODUCTION}

A S IT IS well known, position sensors are necessary in brushless drives in order to provide the correct current waveform supply. High-resolution sensors such as optical encoders or electromagnetic resolvers are required for sinusoidal ac brushless drives, in order to guarantee field orientation and low torque ripple. However, these sensors are costly and delicate, and they require special machine construction, such as a second shaft end to couple the sensor. On the other hand, dc brushless drives are fed with 120 electrical degree square-wave currents, which require a $60^{\circ}$ resolution in rotor position sensing. In this case, inexpensive Hall-effect sensors are sufficient. As a result, a relatively inexpensive drive can be built, although the tradeoff consists of reduced performances and increased torque ripple.

The position sensorless approach to surface-mounted permanent-magnet (PM) machine control is still an open matter,

Paper IPCSD-05-089, presented at the 2004 Industry Applications Society Annual Meeting, Seattle, WA, October 3-7, and approved for publication in the IEEE TRANSACTIONS ON INDUSTRY APPLICATIONS by the Industrial Drives Committee of the IEEE Industry Applications Society. Manuscript submitted for review January 31, 2005 and released for publication December 6, 2005.

F. Giulii Capponi, G. De Donato, L. Del Ferraro, and O. Honorati are with the Department of Electrical Engineering, University of Rome "La Sapienza," Rome 00184, Italy (e-mail: fabio.giuliicapponi@uniroma1.it; giulio. dedonato@uniroma1.it; luca.delferraro@uniroma1.it; onorato.honorati@ uniroma1.it).

M. C. Harke and R. D. Lorenz are with the Department of Mechanical Engineering, University of Wisconsin, Madison, WI 53706-1572 USA (e-mail: harke@cae.wisc.edu; lorenz@engr.wisc.edu).

Digital Object Identifier 10.1109/TIA.2005.863904 and several solutions have been proposed, but none completely solve the problem. Rotor position can be estimated using the back electromotive force (EMF) [1], [2]. These methods generally work well, but fail at very low and zero speeds. Although these machines are nonsalient, high-frequency injection methods can still be used [3]: However, these methods require usage of a consistent portion of the dc-bus voltage and are quite sensitive to different load conditions. To guarantee a full range of operation for a nonsalient machine-including rejecting disturbances at zero speed-position sensors are still required.

Using digital Hall-effect sensors and some additional hardware, a sinusoidal brushless drive has been proposed by Morimoto et al. [4]. High-resolution position information is obtained by processing the low-resolution position measurement and by assuming the velocity to be constant throughout a $60^{\circ}$ sector, equal to the average velocity in the previous sector. Such an algorithm cannot be used at startup and when accelerating or decelerating at low speeds due to the increased error in position estimation. The authors propose a squarewave startup that allows the drive to start in the correct direction and accelerate until a speed that allows low position estimation error is attained.

Bu et al. [5] proposed a software implementation that can substitute the extra hardware introduced in [4] and work correctly even at low speeds. The rotor position estimation error is reset every time the rotor's magnetic axis enters a new $60^{\circ}$ sector, since the low-resolution sensors are able to give a correct position value every $60^{\circ}$. This allows proper control at low speeds, although startup is not thoroughly studied.

In [6], an improved position estimation algorithm is presented, adopting a position estimation error compensation taking into account the $q$-axis reference current. This algorithm can function properly also at startup.

Giulii Capponi et al. [7] proposes a dc brushless startup algorithm that allows the drive to start in the correct direction and reach a minimum speed that allows correct position estimation and thus proper ac brushless operation. This minimum speed is proven to be much lower than the one adopted in [4].

In [8], a similar algorithm to the one described in [4] is proposed, but the authors compensate for the load influence on position measurement. The startup algorithm is similar to the one proposed in [7].

In this paper, the control scheme that was proposed in [7] and that is schematically represented in Fig. 1 is 


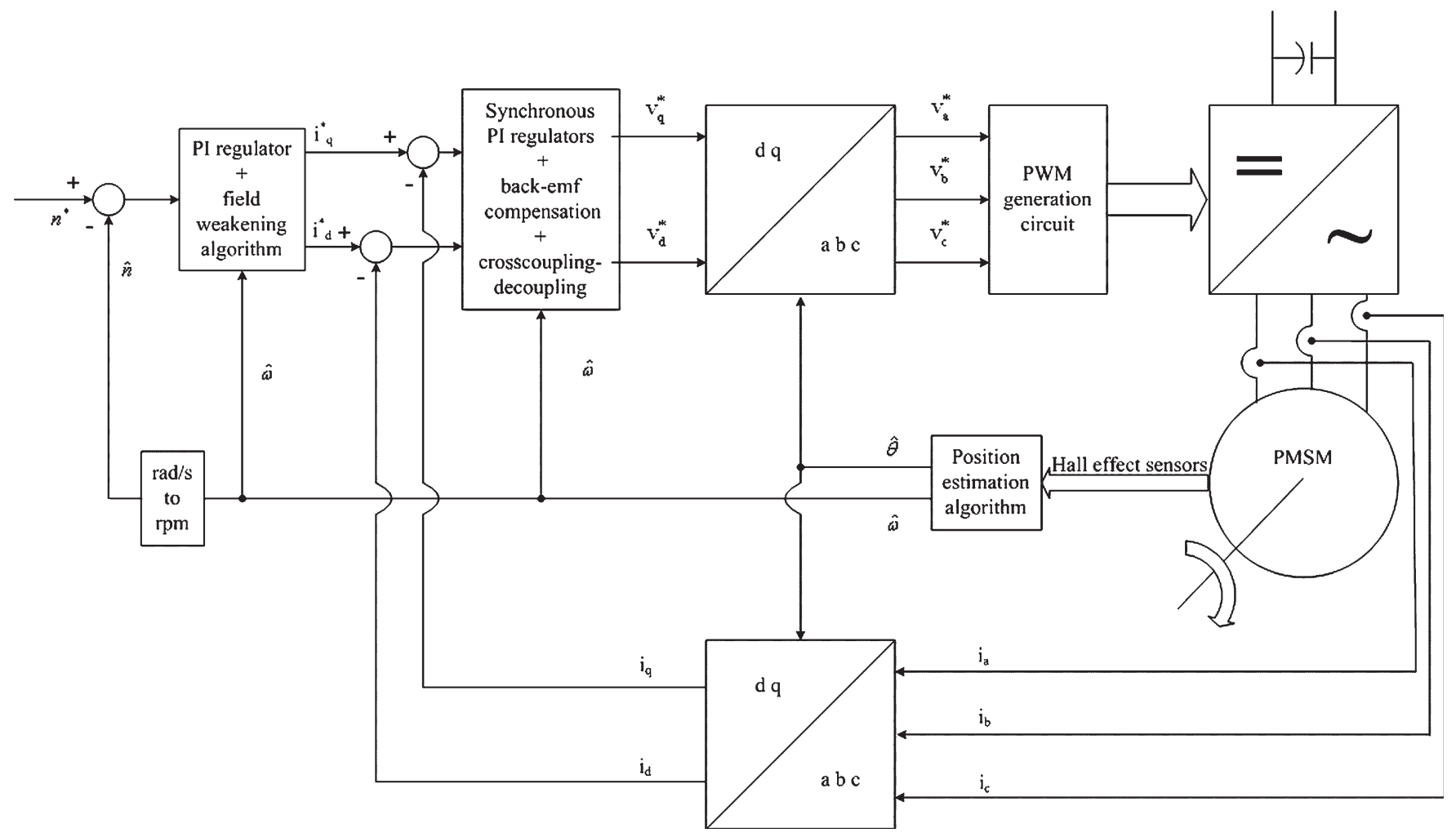

Fig. 1. Block diagram of the proposed brushless drive.

further studied and improved. Three types of position estimation algorithms are presented and compared. Such a drive can be considered as an intermediate solution between the traditional sensored and the position-sensorless brushless drives. The proposed control algorithm's most innovative feature is its adaptability to the whole speed range, including startup, when using any of the three estimation algorithms. The entire control algorithm has been implemented and tested in order to drive a slotless axial-flux PM machine devoted to domestic appliance applications [11], [12], even though the results are general and can be applied to any surface-mounted PM machine.

\section{Position Estimation Algorithms}

High-resolution rotor position estimation is obtained through digital signal processing of the sensors' outputs.

The sensors detect when the rotor's magnetic axis enters a new $60^{\circ}$ sector. The electric angular position is generally expressed as

$$
\theta(t)=\int_{t_{k}}^{t} \omega(t) d t+\theta_{k}
$$

where $\omega(t)$ is the instantaneous electric angular velocity, $t_{k}$ is the instant in which the magnetic axis enters sector $k(k=1$, $2, \ldots, 6)$ and $\theta_{k}$ is the initial angle of sector $k$, measured from a fixed reference axis.

Three different position estimation algorithms have been studied and compared-two are based on the Taylor series expansion and the third is a vector-tracking observer.

\section{A. Zeroth-Order Algorithm}

The zeroth-order position estimation algorithm, introduced in [4], is obtained by taking into account only the zerothorder term of an approximated Taylor series expansion. This algorithm considers the speed inside each sector to be constant and equal to the average velocity in the previous sector. Rotor speed can then be approximated as

$$
\omega(t) \cong \hat{\omega}_{0 k}=\frac{\frac{\pi}{3}}{\Delta t_{k-1}}
$$

where $\Delta t_{k-1}$ is the time interval taken by the rotor's magnetic axis to cross the previous sector $k-1$.

The electric angular position can be obtained by numerical integration of (1), applying the constraint that the resulting angular position value has to be within sector $k$ limits. The angular position is, thus, calculated as

$$
\begin{aligned}
\hat{\theta}_{0}(t) & =\theta_{k}+\hat{\omega}_{0 k}\left(t-t_{k}\right) \\
\theta_{k} & \leq \hat{\theta}_{0}(t) \leq \theta_{k}+\frac{\pi}{3} .
\end{aligned}
$$

\section{B. First-Order Algorithm}

The rotor speed can be approximated to a better degree by taking into account higher order terms of the Taylor series expansion [7]. The first-order estimation algorithm is given as

$$
\omega(t) \cong \hat{\omega}_{1 k}(t)=\hat{\omega}_{0 k}+\hat{\omega}_{1 k}^{(1)}\left(t-t_{k}\right)
$$




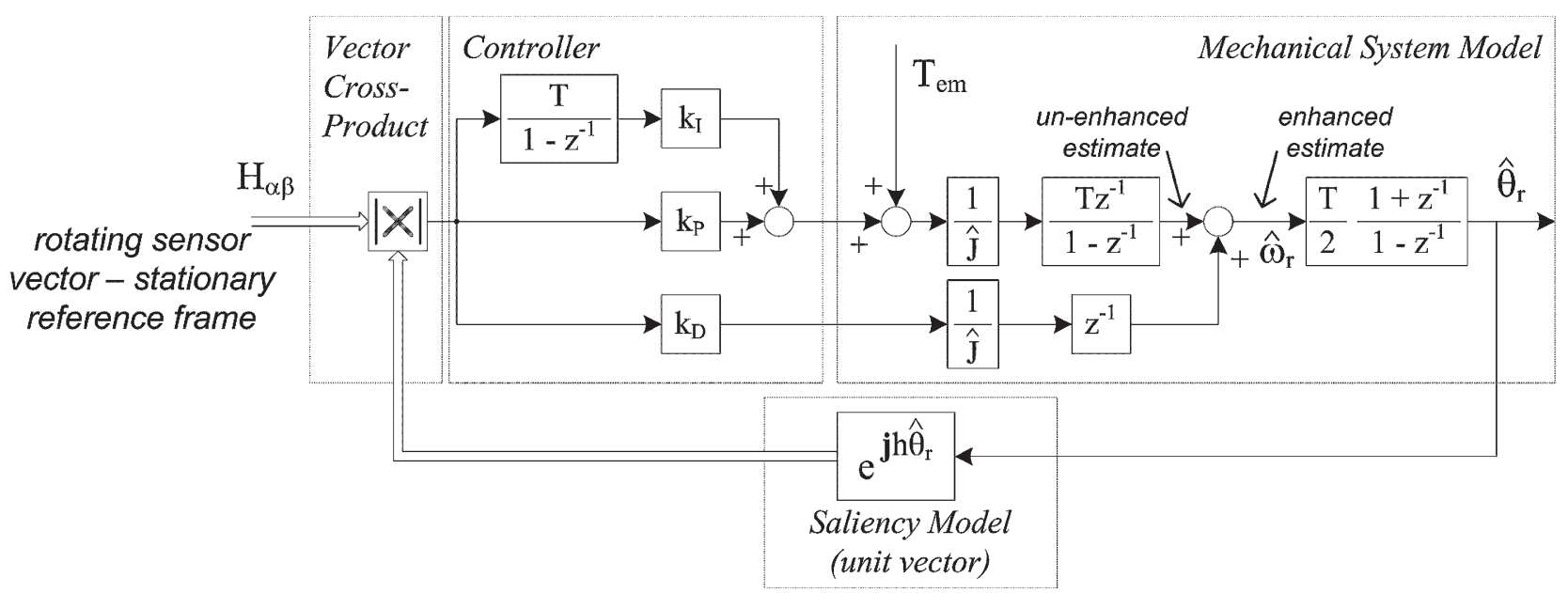

Fig. 2. Discrete-time vector-tracking observer.

In (4), the first derivative is approximated as

$$
\hat{\omega}_{1 k}^{(1)}=\frac{\hat{\omega}_{0 k}-\hat{\omega}_{0(k-1)}}{\Delta t_{k-1}} .
$$

The electric angular position comes out to be

$$
\begin{aligned}
\hat{\theta}(t) & \cong \hat{\theta}_{1}(t)=\theta_{k}+\hat{\omega}_{0 k}\left(t-t_{k}\right)+\frac{\hat{\omega}_{1 k}^{(1)}}{2}\left(t-t_{k}\right)^{2} \\
\theta_{k} & \leq \hat{\theta}_{1}(t) \leq \theta_{k}+\frac{\pi}{3} .
\end{aligned}
$$

Although it is possible to use higher order approximations, only the first-order one has been considered because of increasing computational times.

\section{Vector-Tracking Observer}

A different way to approach position estimation is to use a vector-tracking phase-locked loop. The same observer structure has already been used in [9] for Interior PM machine sensorless control. Furthermore, in [10], the vector tracking observer is proposed in order to estimate rotor position from a quantized rotating vector with limited resolution, examining the performance of a low-resolution encoder ( $1^{\circ}$ angular resolution) at steady state. The vector-tracking observer is used here in a new and original fashion; startup and steady-state performances are evaluated, both in simulation and experimentally.

The vector-tracking observer structure, Fig. 2, has two inputs: 1) a rotating vector containing position information and 2) a torque feedforward input to the mechanical model that provides position tracking above the observer bandwidth. The proportional-integral-differential (PID) controller is used to force convergence. A rotating unit-vector based on the observed position is used as feedback to the phase detector. The estimated position is calculated using a latched-torque model of a simple rotational system.

The rotating vector is obtained by processing the sensors' signals. The six possible combinations of the sensors' states

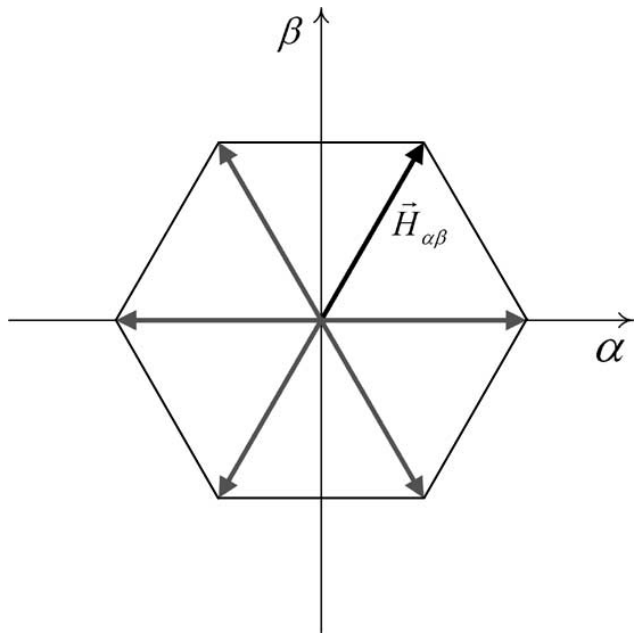

Fig. 3. Stationary reference frame sensors' vector $\vec{H}_{\alpha \beta}$.

can be interpreted as the vertices of a hexagon locus in the stationary reference frame, Fig. 3 . Here the rotating vector $\vec{H}_{\alpha \beta}$ is in the $60^{\circ}$ position; this means that the rotor magnetic axis is somewhere between $60^{\circ}$ and $120^{\circ}$. While the rotor axis crosses a $60^{\circ}$ sector, the rotating vector remains in a fixed position, since there are only six possible states.

A consideration of tuning the vector-tracking observer given the quantized nature of the Hall-effect sensors is that the sample rate of the motor position depends on the motor speed. Between transitions of the Hall sensor signal output, the observer relies on the feedforward torque command to estimate the rotor position. If the observer bandwidth is set too high, the resulting position estimate will be quantized. To solve this problem, the observer bandwidth should be speed dependent until a desired bandwidth is attained.

\section{Startup And High SpeEd Considerations}

All three position estimation algorithms can be used only for rotor speeds within a certain range, as described in the following paragraphs. 


\section{A. Zeroth- and First-Order Algorithms}

The minimum speed $\left(\omega_{\min }\right)$ is determined by the fact that the initial hypothesis of a constant speed over an entire sector does not hold for very low speeds; added to this is the fact that the velocity may become so low that, in practical digital implementations, the timer used for time measurement overflows before the whole sector is crossed. The maximum speed $\left(\omega_{\max }\right)$ is determined in theory by the timer's resolution and in practice by the loss of resolution if the speed range becomes too large. In the proposed drive, the minimum speed at which the position estimation algorithm is used has been set to $12 \mathrm{r} / \mathrm{min}$ ( $0.8 \mathrm{~Hz}$ supply frequency); the maximum speed has been set to $3000 \mathrm{r} / \mathrm{min}$ (200-Hz supply frequency).

As there is a minimum speed under which these estimation algorithms cannot work properly, at startup, a $120^{\circ}$ square-wave current control law has been considered to be the most suitable. In [7], it was shown how a bumpless transition between dc brushless and ac brushless modes of operation can be achieved by appropriately choosing the current reference amplitude and the rotor position when the transition occurs.

\section{B. Vector-Tracking Observer}

This algorithm does not have the startup problems encountered by the Taylor series algorithms: The drive is started directly in ac brushless mode. Convergence problems cannot arise, since the initial value of $\hat{\theta}$ is set to the value obtained by the low-resolution sensors: The maximum error on the initial angle is, in this way, reduced to $60^{\circ}$ and therefore startup is always possible. High speed problems are encountered only above the observer's bandwidth: In this region, the observer behaves as an open-loop observer, being the feedforward signal its only input. This means that the observer will encounter problems in velocity and position estimation if there is an error in the estimated inertia $\hat{J}$. However, assuming that the observer bandwidth and motor motion controller bandwidth are similar, these accuracy errors are above the motor controller bandwidth and have a negligible effect on performance.

\section{Simulations}

Simulations have been carried out with Matlab Simulink to study the behavior of the three position algorithms in the drive's control algorithm. The outer speed loop was tuned to have an 80-Hz bandwidth.

\section{A. Zeroth-Order Estimation Algorithm}

Figs. 4 and 5 show the performance of the speed estimation of the zeroth-order estimation algorithm when it is used in the feedback loop of the proposed drive. In particular, Fig. 4 shows the speed transient that follows a step speed command from 0 to $100 \mathrm{rad} / \mathrm{s}$; in accordance with the experimental setup, a linear speed-dependent load is included in the model, so that at $100 \mathrm{rad} / \mathrm{s}$, the motor is working at nominal load conditions. Fig. 5 shows the speed estimation error between the mechanical speed and the estimated speed; a smaller vertical scale has been used in this figure, because the error is small after only $0.5 \mathrm{~s}$

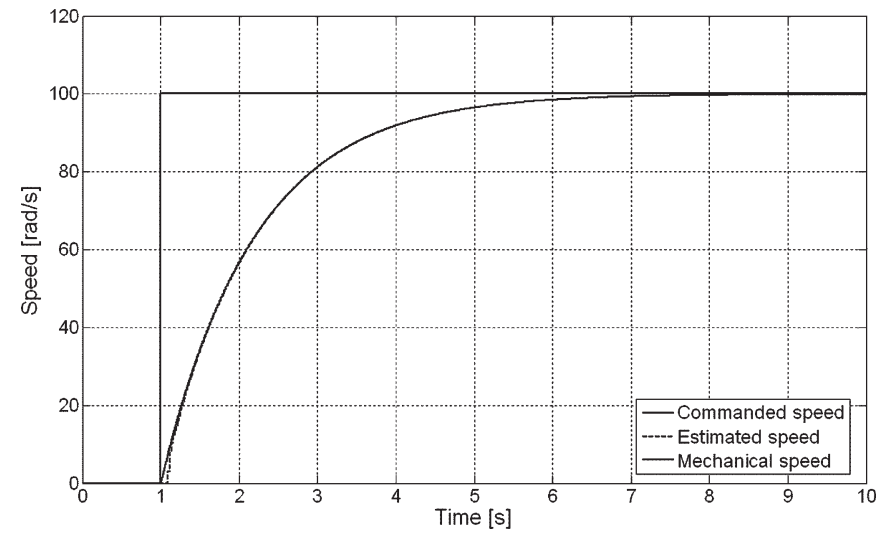

Fig. 4. Mechanical and estimated speed following a step speed command from 0 to $100 \mathrm{rad} / \mathrm{s}$ using the zeroth-order algorithm.

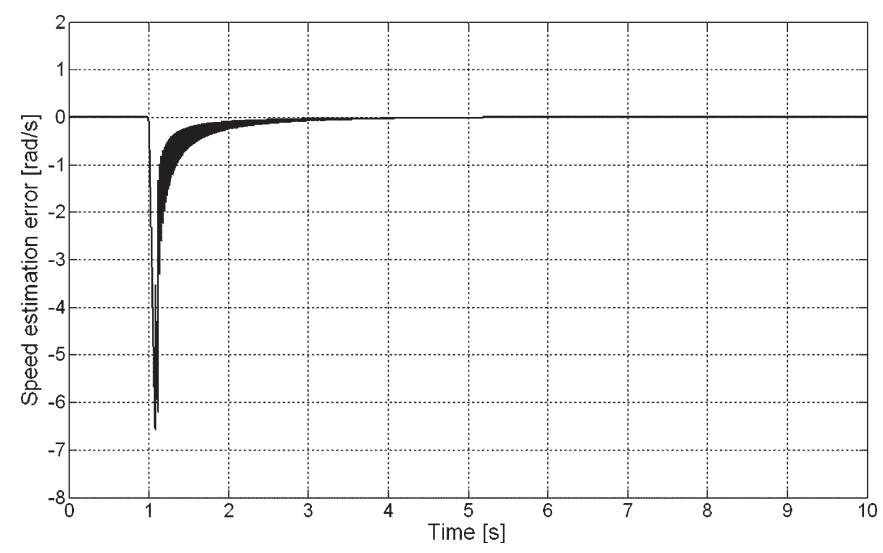

Fig. 5. Speed estimation error following a step speed command from 0 to $100 \mathrm{rad} / \mathrm{s}$ using the zeroth-order algorithm.

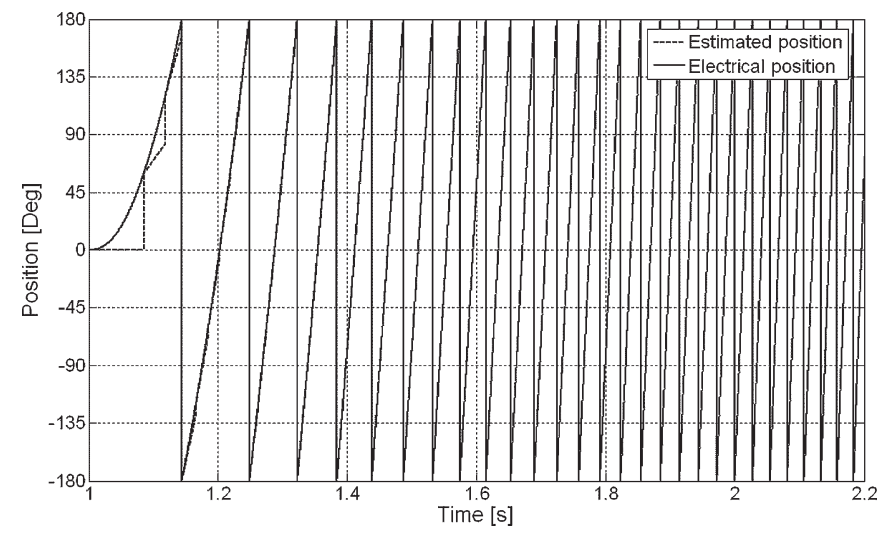

Fig. 6. Electrical and estimated position following a step speed command from zero to $100 \mathrm{rad} / \mathrm{s}$ using the zeroth-order algorithm.

from startup. It can be noticed that the error is initially quite large. This is due to the fact that although the speed is low, there is a strong acceleration, so after the first $60^{\circ}$ the average velocity is much greater than zero (estimated speed for the first sector); this strong difference between average speed in the previous sector and actual velocity is the cause of the initial error.

Figs. 6 and 7 show the performance of the position estimation. Fig. 6 shows that the acceleration is such that the drive operates in dc brushless mode only in the first sector, since the average speed through the first sector is higher than the $12 \mathrm{r} / \mathrm{min}$ 


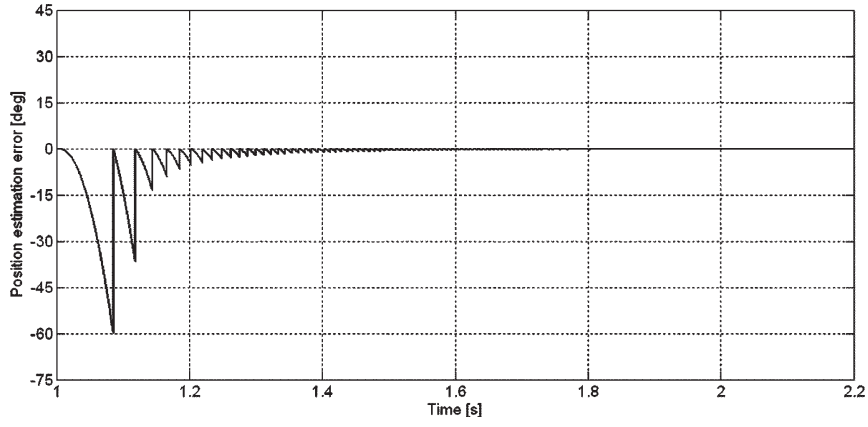

Fig. 7. Position estimation error following a step speed command from 0 to $100 \mathrm{rad} / \mathrm{s}$ using the zeroth-order algorithm.

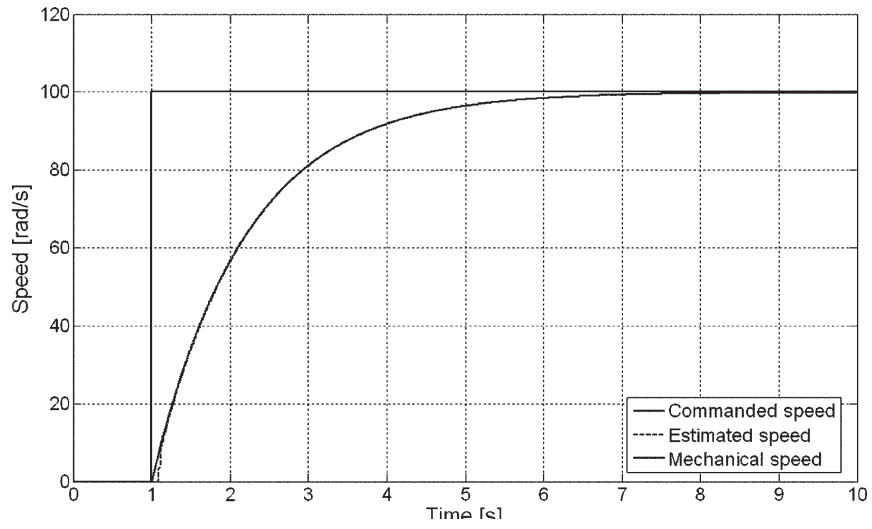

Fig. 8. Mechanical and estimated speed following a step speed command from 0 to $100 \mathrm{rad} / \mathrm{s}$ using the first-order algorithm.

transition speed. Also the corrections in the estimated position at the end of each of the first few sectors are visible. This occurs, because the estimated position lags the real position and is therefore corrected at the beginning of a new sector when fresh information is fed to the algorithm from the lowresolution position sensors. As the speed estimation becomes more precise, the position estimation error decreases quickly. After $200 \mathrm{~ms}$, the maximum position estimation error is less than $5.5^{\circ}$, Fig. 7.

\section{B. First-Order Estimation Algorithm}

Figs. 8 and 9 show the performance of the speed estimation algorithm when it is used in the feedback loop of the proposed drive. Fig. 8 shows the speed transient that follows the same step speed command as above. Fig. 9 shows the speed estimation error between the mechanical speed and the estimated speed. The error remains initially quite large even with this algorithm, but it decays more quickly and in a smoother way after the first few sectors. The velocity is tracked more precisely, since the estimation now uses also an average acceleration term. After about $120 \mathrm{~ms}$, the speed estimation error is lower than $1 \mathrm{rad} / \mathrm{s}$.

Figs. 10 and 11 show the performance of the position estimation. Fig. 10 shows how the position estimation is more precise than the zeroth-order algorithm; the correction at the end of the sector is practically null after the first two sectors, and can also

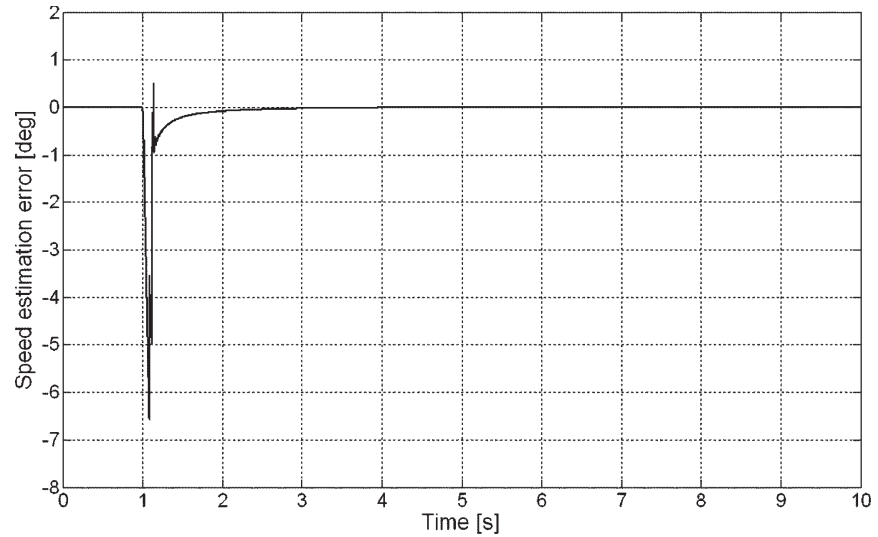

Fig. 9. Speed estimation error following a step speed command from 0 to $100 \mathrm{rad} / \mathrm{s}$ using the first-order algorithm.

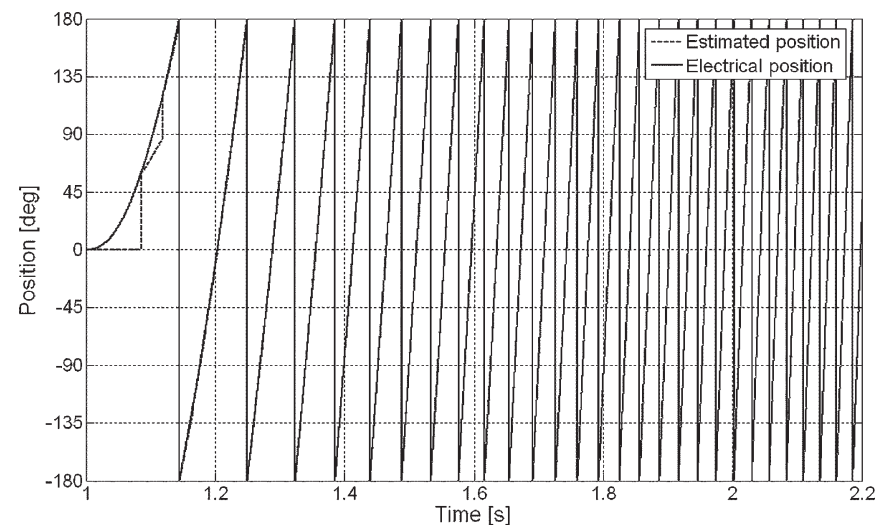

Fig. 10. Electrical and estimated position following a step speed command from zero to $100 \mathrm{rad} / \mathrm{s}$ using the first-order algorithm.

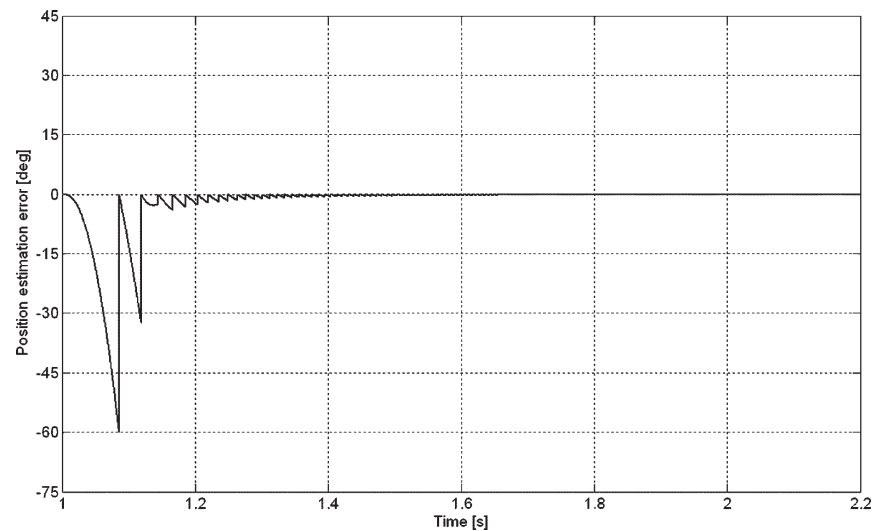

Fig. 11. Position estimation error following a step speed command from 0 to $100 \mathrm{rad} / \mathrm{s}$ using the first-order algorithm.

be seen in Fig. 11, which shows the error between the actual and estimated position.

\section{Vector-Tracking Observer}

The observer has been tuned to have the following bandwidths: [80, 2, 0.2] Hz. Fig. 12 shows the speed transient when using the vector-tracking observer. As can be seen in Fig. 2, 


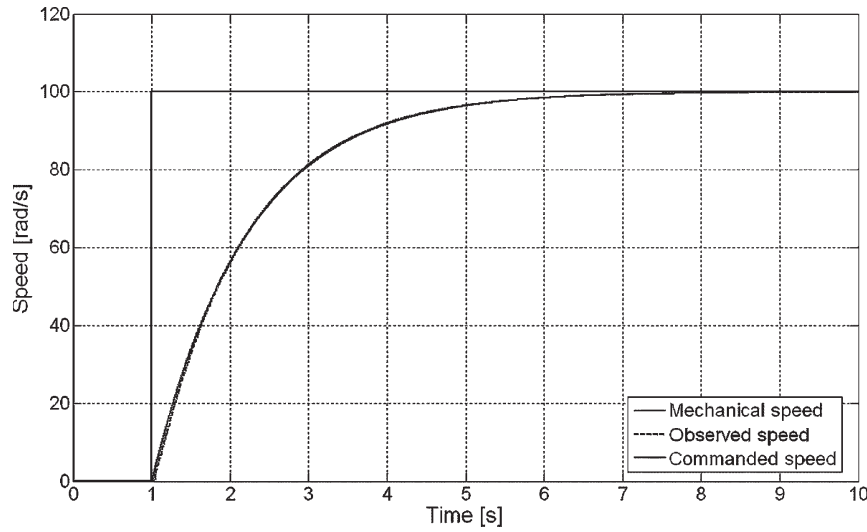

Fig. 12. Mechanical and unenhanced observed speed following a step speed command from 0 to $100 \mathrm{rad} / \mathrm{s}$ using the vector-tracking observer.

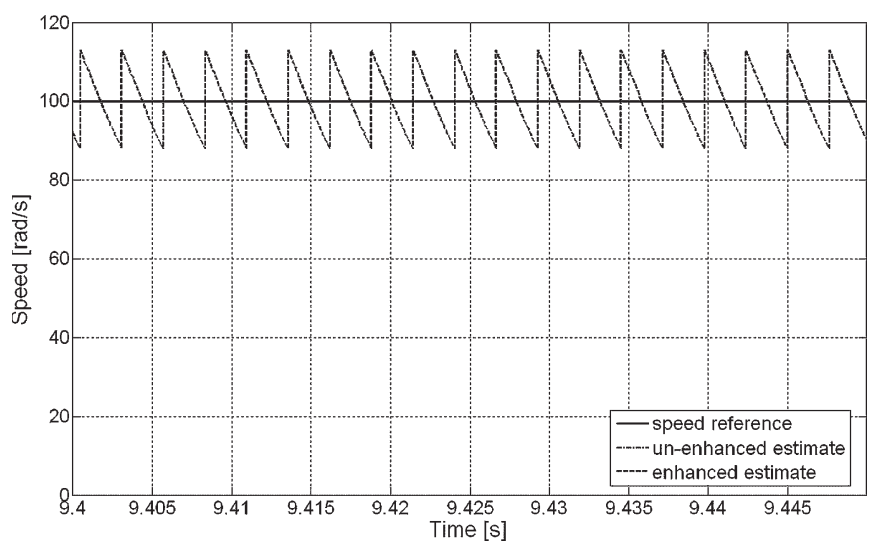

Fig. 13. Enhanced versus un-enhanced speed observation at steady state using the vector-tracking observer.

this observer inherently has two speed signals, namely: 1) the un-enhanced speed signal, which is equal to the integral of the acceleration signal and 2) the enhanced speed signal, which is the sum of the un-enhanced speed signal and the derivative term of controller. Both may be used as the observed speed in the current and speed loops, however, they have different properties. In this application, in which position information has a very low resolution, the different behavior is easily visible at steady state, as shown in Fig. 13. The un-enhanced speed signal is undistinguishable from the speed reference: This is due to the fact that it does not contain the derivative term of the controller. This component, which is present in the enhanced counterpart, is necessary to maintain observer stability. The unenhanced speed signal guarantees a smaller steady-state speed error, albeit at a reduced estimation bandwidth. However, assuming the motion controller and observer are tuned consistently, the ripple of the enhanced estimate does not adversely affect the motion control, but allows for higher disturbance rejection. Fig. 14 shows the speed observation error; it can be noticed that although the error takes longer to reach steady state, compared to the Taylor series algorithms, the error is very small during the initial part of the speed transient: This is due to the phase tracking nature of the observer. The convergence is oscillatory due to two different reasons, namely: 1) the dynamic nature of the observer, which accounts for the slower oscillatory mode

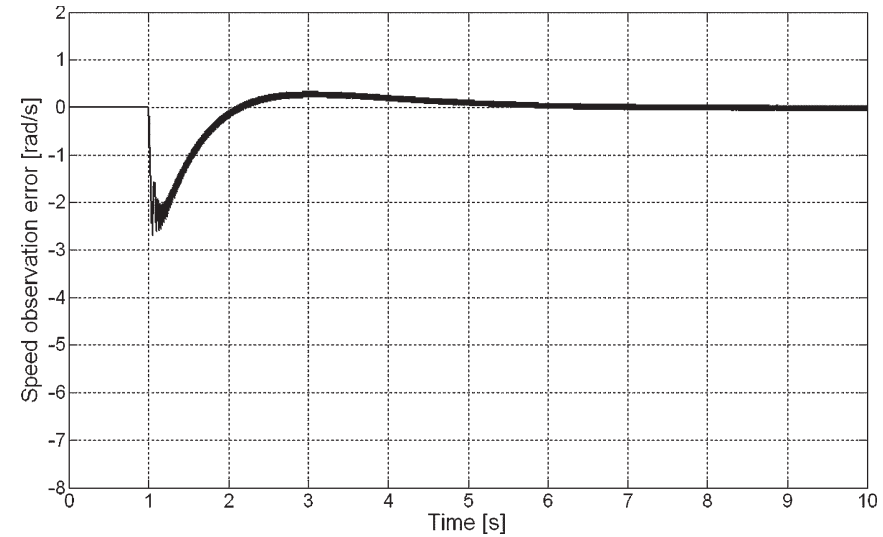

Fig. 14. Speed observation error following a step speed command from 0 to $100 \mathrm{rad} / \mathrm{s}$ using the vector-tracking observer.

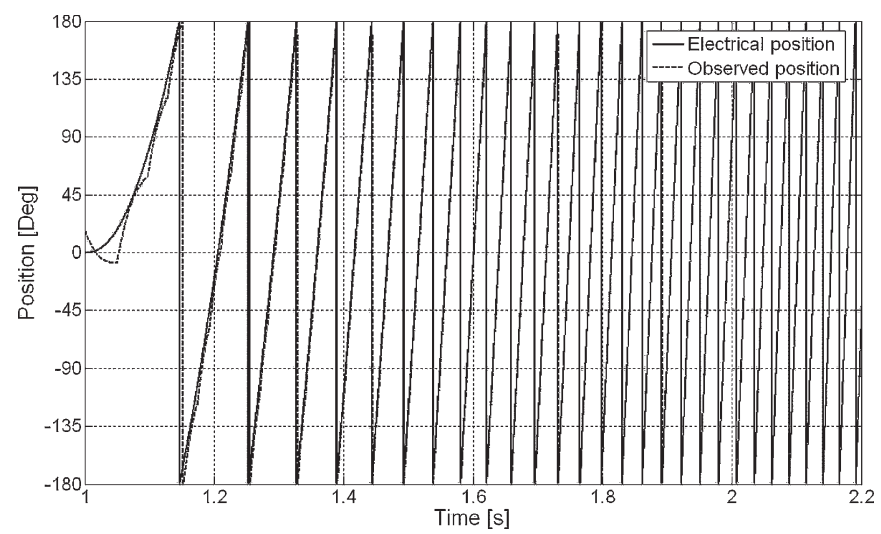

Fig. 15. Electrical and observed position following a step speed command from 0 to $100 \mathrm{rad} / \mathrm{s}$ using the vector-tracking observer.

and 2) the low-resolution position information, which accounts for the higher frequency oscillations.

Fig. 15 shows the performance of the position observation. The observed position initially anticipates the real electrical position and then converges when information from the Halleffect sensors is obtained; such a behavior is confirmed in Fig. 16 in which the error in position observation oscillates toward a steady state. The reasons for this behavior are the same as for the speed observation.

The vector-tracking observer has by far the best dynamic behavior: Both the maximum errors on speed and position during the rise time are reduced to less than $45 \%$ with respect to the Taylor series algorithms.

\section{EXPERIMENTAL RESUlts}

A drive prototype for home appliance applications, composed of an axial-flux PM machine, a low-cost full-bridge insulated gate bipolar transistor (IGBT) inverter and a 16-bit fixed-point digital signal processor (DSP) in which the aforementioned control algorithm resides, has been built and tested. The adopted axial-flux machine has surface-mounted PM and slotless stator windings; thus its structure is highly isotropic and it exhibits very low inductance, which makes this machine a very good candidate to test the algorithms under 


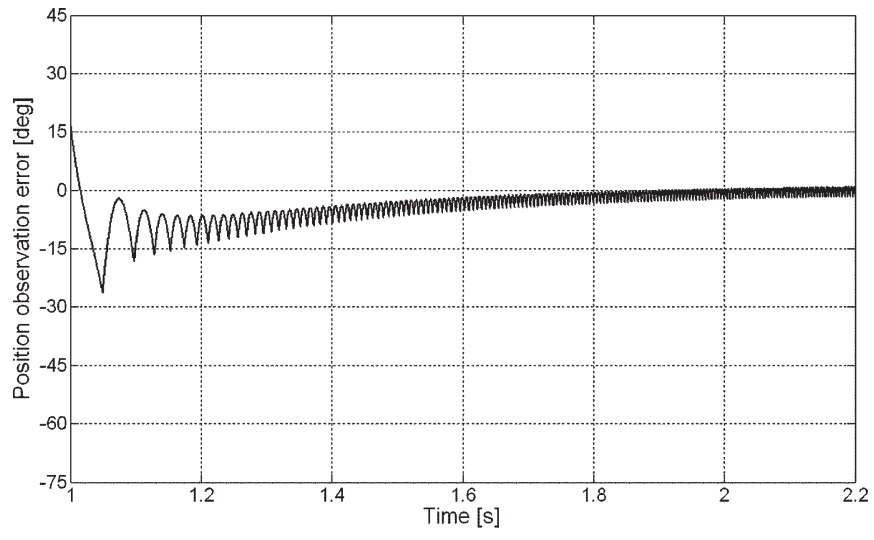

Fig. 16. Position observation error following a step speed command from 0 to $100 \mathrm{rad} / \mathrm{s}$ using the vector-tracking observer.

TABLE I

Rated Values of The Motor PRototype

\begin{tabular}{ll}
\hline \hline Rated power & $500 \mathrm{~W}$ \\
Rated frequency & $200 \mathrm{~Hz}$ \\
Number of poles & 8 \\
Rated speed & $3000 \mathrm{rpm}$ \\
Rated voltage & $150 \mathrm{~V}$ \\
Rated current & $2.24 \mathrm{~A}$ \\
Rated efficiency & $90 \%$ \\
Total weight of active parts & $0.94 \mathrm{~kg}$ \\
\hline \hline
\end{tabular}

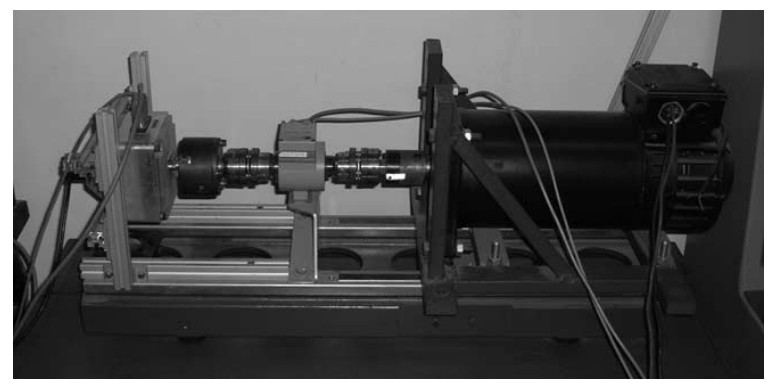

Fig. 17. Prototype axial-flux machine (on the far left) at the test bench.

investigation. In Table I, the main design characteristics of the motor are presented, while Fig. 17 shows the machine at the test bench. The inverter switching frequency is set to $15 \mathrm{kHz}$ and the dead time is $2.5 \mu \mathrm{s}$. An incremental encoder has been mounted on the drive's shaft only to allow a comparison between the estimated angle and a high-resolution measurement. A linear speed-dependent load is coupled to the motor shaft so that at $100 \mathrm{rad} / \mathrm{s}$, the motor is working at nominal load conditions. The following subparagraphs describe the experimental results obtained using all the previously described algorithms.

\section{A. Zeroth-Order Algorithm}

Experimental results with the zeroth-order algorithm show a good accordance with the simulations. Fig. 18 shows the position estimation algorithm when the drive is functioning at very low speed. Position correction can be seen at the end of each $60^{\circ}$ sector. Position estimation saturation can be seen

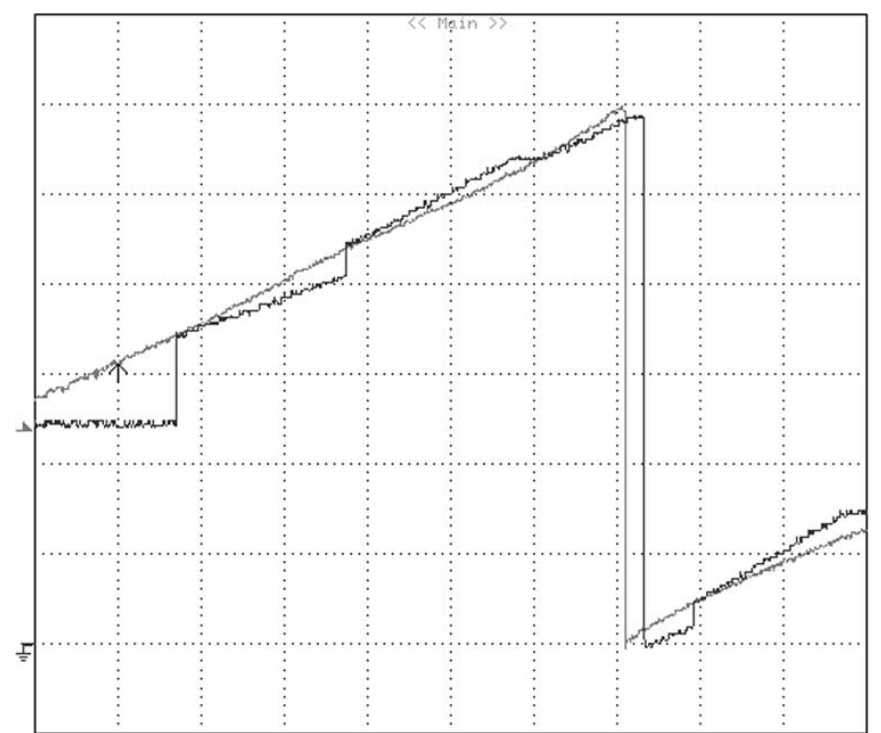

Fig. 18. Estimated and measured angular position $\left(60^{\circ} / \mathrm{div}\right)$ at near-minimum ac brushless operation speed.

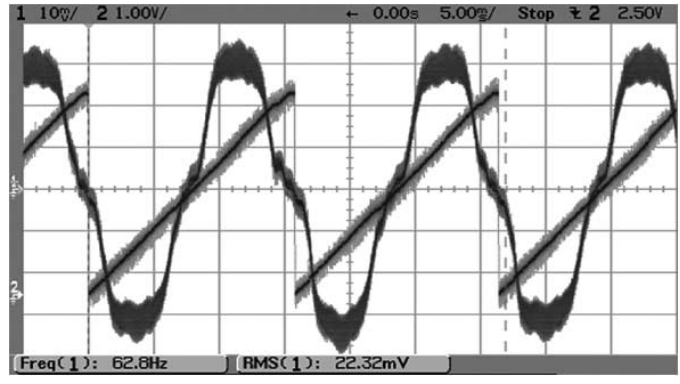

Fig. 19. Estimated angular position and phase current (1 A/vertical div, $5 \mathrm{~ms} /$ horizontal div) at rated load torque and $100 \mathrm{rad} / \mathrm{s}$.

toward the end of the third sector: This is due to the fact that the average velocity in the second sector, which is used by the algorithm in the third sector, is higher than the actual average velocity in the third sector, so the estimation algorithm reaches the end of the sector before the physical system. The algorithm corrects itself by saturating its position estimation until a new sector is actually entered.

Fig. 19 shows the performance of the drive at steady state.

\section{B. First-Order Algorithm}

Experimental results have shown that the performances of the first-order algorithm are not as satisfactory as simulations predicted. Fig. 20 shows that the estimated angular acceleration given in (5) varies a great deal from one sector to another, even at steady speed; in the drive under test, a periodic nature has been registered in this variation, with a period equal to the mechanical period (four times the electric period). Analysis of this behavior evidenced that the phenomenon is caused by slight differences in the angular width of each sector. Possible reasons for this are Hall-effect sensors hysteresis, imprecise positioning of the sensors, differences in the field produced by adjacent magnets, etc. In this case, even at constant speed, 


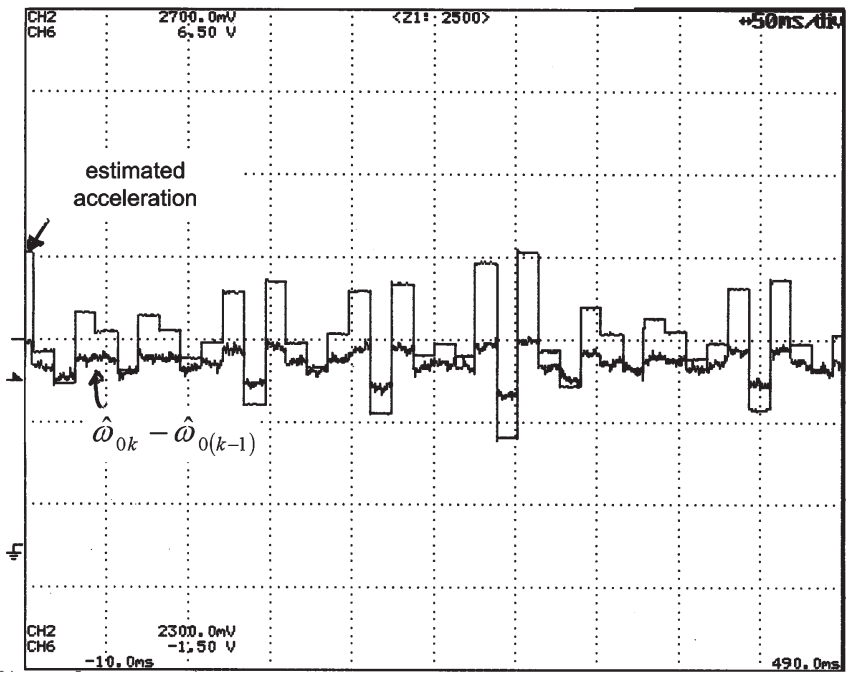

Fig. 20. Estimated acceleration and estimated speed difference between two adjacent sectors.

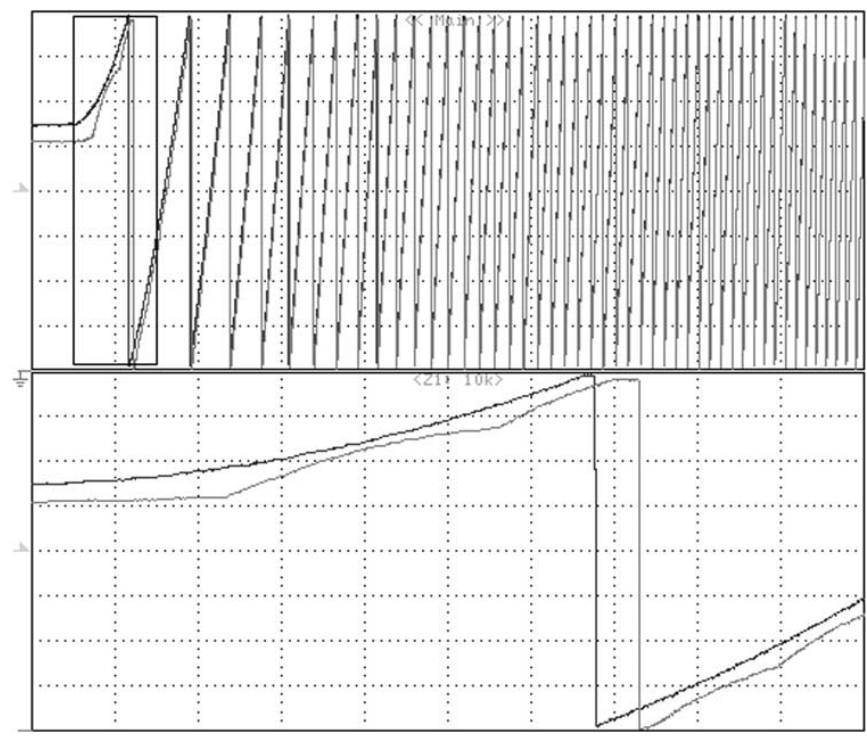

Fig. 21. Measured electrical and observed position following a step speed command from 0 to $100 \mathrm{rad} / \mathrm{s}$ using the vector-tracking observer $(45 \%$ vertical div and $200 \mathrm{~ms} /$ horizontal div).

any difference in sector width from the exact $60^{\circ}$ causes the estimated acceleration to be different from zero. Most likely, one sector will be bigger and the next one smaller than $60^{\circ}$. Then, the estimated acceleration will switch continuously from negative to positive values, generating a signal affected by a lot of noise. Moreover, it can also be shown that such a noise is proportional to the square of the angular velocity. The angular acceleration signal is too noisy to be employed as it is inside the estimation algorithm. On the other hand, signal filtering cannot be performed, since, otherwise, the effect of the acceleration term will be too slow to be effective. These considerations allow us to conclude that, with low-cost sensors, the first-order algorithm cannot be used, and therefore it is useless to even consider adopting higher order approximations for position estimation.

\section{Vector-Tracking Observer}

Practical implementation of the vector-tracking observer on the 16-bit DSP included the use of 32-bit arithmetic to be able to obtain sufficient resolution on the controller gains, an important feature in order to guarantee correct dynamic behavior of the observer. However, this did not constitute a problem, since 32-bit arithmetic on a 16-bit processor is a well-known issue and routines that tackle this problem are easily available. In addition, since the programming was done in assembly language, there was no significant problem in computational times, the entire control algorithm being less than $50 \mu \mathrm{s}$, well within the $66.67 \mu$ s calculation time limit for the $15-\mathrm{kHz}$ pulsewidth modulation (PWM).

The sample time for the observer was set to $266.67 \mu$ s (3.75 kHz), a compromise between maximum resolution on the position estimation at high speeds and resolution on the observer controller gains. In fact, a lower sample time increases the resolution on position estimation, but in order to obtain the same dynamic performances, the observer gains become smaller. The smaller the gains become, the greater the number of bits necessary to have the desired resolution. However, if precise control at very high shaft speeds (for example, operation well into the field weakening region) is necessary, then the best solution is to use a 32-bit DSP, easily available and at increasingly lower cost, which practically eliminates any type of resolution issues.

Experimental results show very good accordance with simulations. Fig. 21 shows the observer performance at startup; the behavior is the same as predicted in simulation in Fig. 14 . A zoom is made at startup to show the actual convergence of the observed position toward the measured position; as can be seen, there is a $30^{\circ}$ initial error between the two signals due to the fact that at zero speed, the position is unknown and unobservable. However, both startup in the correct direction and zero steady-state error are achieved. Furthermore, the position observation error shown in Fig. 22 follows closely the simulated behavior in Fig. 15. Fig. 23 shows steady-state performance of the proposed drive when using the vector-tracking observer. The estimated and actual position, the position estimation error and the phase current are shown. It can be seen that correct field orientation is obtained and the average error in position observation is $0^{\circ}$. However, the error presents two types of oscillations, namely: 1) a low-frequency ripple mainly due to the imperfect positioning of the Hall-effect sensors; and 2) a high-frequency ripple (equal to six times the electrical frequency) due to the low-resolution position measurement. In this case, the error in sensor positioning does not affect proper functionality of the observer, thus showing the superiority of this solution to the Taylor algorithms, even regarding sensitivity to sensor misplacement or inaccuracy. Finally, in Fig. 24, the zeroth-order speed estimate and the unenhanced observed speed are compared experimentally, confirming the simulation results shown in Figs. 4 and 12. It can be seen that the unenhanced observed speed is practically a zero-lag filtered version of the speed signal; the first property theoretically descends from the use of the torque feedforward, and the second from the closedloop nature of the observer. As a confirmation of the first 


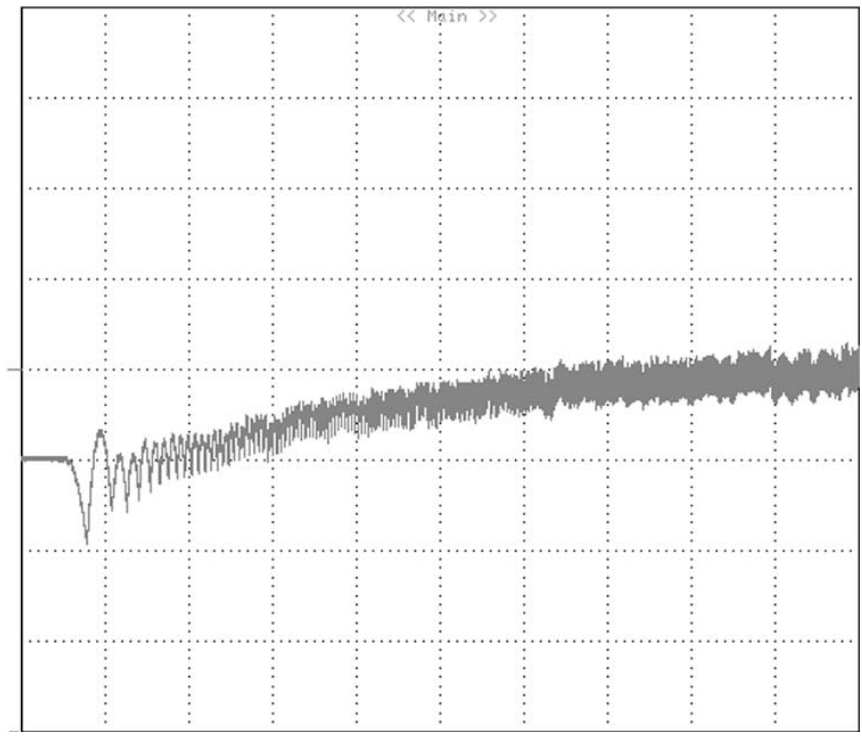

Fig. 22. Measured position observation error following a step speed command from 0 to $100 \mathrm{rad} / \mathrm{s}$ using the vector-tracking observer $\left(15^{\circ} /\right.$ vertical div and $200 \mathrm{~ms}$ /horizontal div).

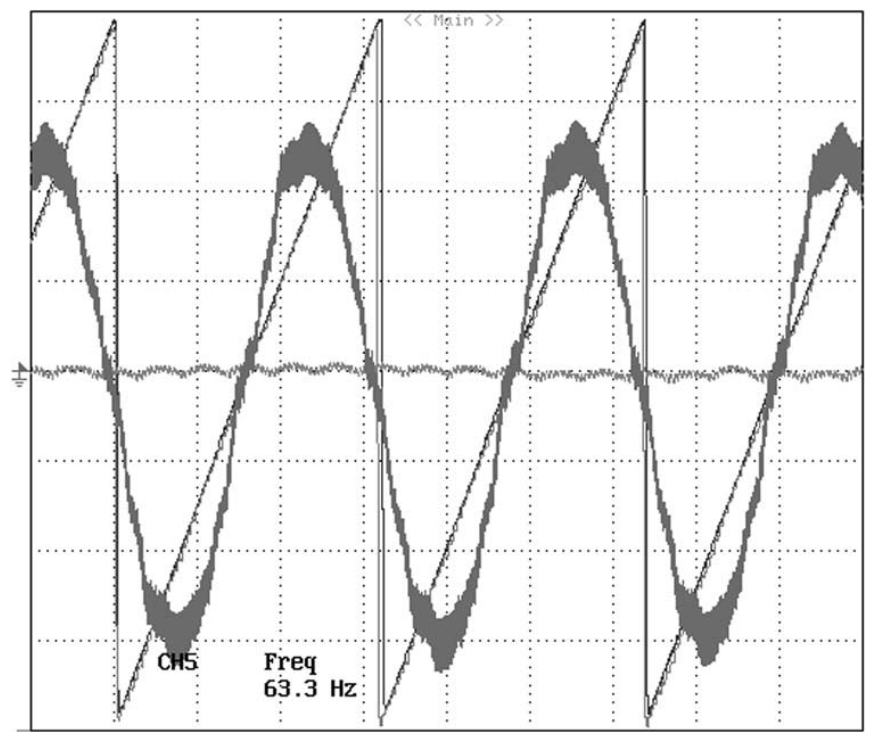

Fig. 23. Measured steady state current, measured electrical position, observed position, and position observation error at $100 \mathrm{rad} / \mathrm{s}(1 \mathrm{~A} / \mathrm{vertical} \mathrm{div}, 45 \%$ vertical div, and $5 \mathrm{~ms} /$ horizontal div).

property, it can be seen in Fig. 24 that the zeroth-order speed estimate initially lags the unenhanced observed speed; this is due to the fact that in the first sector, the speed is set to zero by the zeroth-order estimation algorithm. The second property is easily confirmed by visual inspection of both signals.

\section{CONCLUSION}

In this paper, an innovative brushless ac drive has been presented. Such a drive attempts to overcome some limitations of traditional brushless ac drives concerning the use of highresolution position sensors. The control algorithm's most innovative feature is its adaptability to the whole speed range including startup. Three different types of speed and position estimation algorithms have been presented and compared theo-

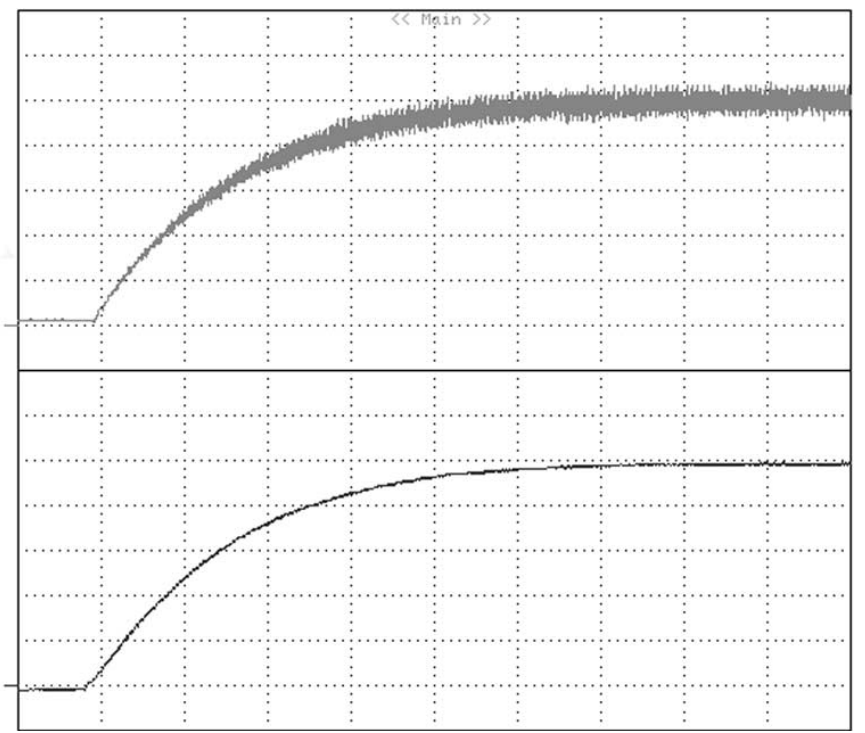

Fig. 24. Zeroth-order speed estimate and unenhanced observed speed following a step speed command from 0 to $100 \mathrm{rad} / \mathrm{s}$ (20 rad/s vertical div and $1 \mathrm{~s} /$ horizontal div)

retically, in simulation, and experimentally. The experimental results show that when using the vector-tracking observer, the best steady-state and dynamic performances are achieved. Sensor misplacement and inaccuracy is investigated, resulting in the vector-tracking observer yielding the lowest sensitivity. Furthermore, the influence of finite precision calculations and number of bits are considered, and it is shown that, when using a standard fixed-point 16-bit DSP, they do not sensibly influence observer behavior as long as very precise high-speed operation that requires a lower sample period is not necessary. The results are highly satisfactory for the home application that the drive is intended for. Such a drive is ideal in low-cost applications or in any other application that does not require either constant torque at very low speeds or position tracking.

\section{REFERENCES}

[1] H. A. Toliyat, L. Hao, D. S. Shet, and T. A. Nondahl, "Position-sensorless control of surface-mount permanent-magnet AC (PMAC) motors at low speeds," IEEE Trans. Ind. Electron., vol. 49, no. 1, pp. 157-164, Feb. 2002.

[2] S. Shinnaka, "New 'D-State-Observer' based vector control for sensorless drive of permanent-magnet synchronous motors," IEEE Trans. Ind. Appl., vol. 41, no. 3, pp. 825-833, May/Jun. 2005.

[3] A. Consoli, G. Scarcella, G. Tutino, and A. Testa, "Zero frequency rotor position detection for synchronous PM motors," in Proc. IEEE 31st Annu. Power Electronics Specialists Conf. (PESC), Galway, Ireland, Jun. 2000, vol. 2, pp. 879-884.

[4] S. Morimoto, M. Sanada, and Y. Takeda, "Sinusoidal current drive system of permanent magnet synchronous motor with low resolution position sensor," in Proc. IEEE IAS Annu. Meeting, San Diego, CA, Oct. 1996, pp. 9-13.

[5] J. Bu, L. Xu, T. Sebastian, and B. Liu, "Near-zero speed performance enhancement of PM synchronous machines assisted by low cost Hall effect sensors," in Proc. IEEE Applied Power Electronics Conf. (APEC), Anaheim, CA, Feb. 1998, pp. 68-74.

[6] S. Morimoto, M. Sanada, and Y. Takeda, "High performance currentsensorless drive for PMSM and SynRM with only low resolution position sensor," IEEE Trans. Ind. Appl., vol. 39, no. 3, pp. 792-801, May/Jun. 2003.

[7] F. Giulii Capponi, G. De Donato, and L. Del Ferraro, "Brushless AC drive using an axial flux synchronous motor with low resolution position 
sensors," in Proc. IEEE 35th Annu. Power Electronics Specialists Conf. (PESC), Aachen, Germany, Jun. 2004, vol. 3, pp. 2287-2292.

[8] J. X. Shen, Z. Q. Wong, and D. Howe, "PM brushless drives with lowcost and low-resolution position sensors," in Proc. Power Electronics and Motion Control Conf. (IPEMC), Xi'an, China, Aug. 2004, vol. 2, pp. 1033-1038.

[9] H. Kim, M. C. Harke, and R. D. Lorenz, "Sensorless control of interior permanent-magnet machine drives with zero-phase lag position estimation," IEEE Trans. Ind. Appl., vol. 39, no. 6, pp. 1726-1733, Nov./Dec. 2003

[10] T. Tesch, "Dynamic torque estimation in a sensor limited environment," $\mathrm{Ph} . \mathrm{D}$. preliminary examination presentation, Dept. Mech. Eng., Univ. Wisconsin, Madison, Aug. 2000.

[11] E. Bassi, F. Benzi, A. Braga, F. Giulii Capponi, and F. Caricchi, "Integration of an axial flux motor for home automation," in Proc. IEEE Int. Symp. Ind. Electronics (ISIE), L'Aquila, Italy, Jul. 2002, vol. 2, pp. 111-116.

[12] F. Caricchi, F. Giulii Capponi, F. Crescimbini, and L. Solero, "Sinusoidal brushless drive with low-cost hall effect position sensors," in Proc. IEEE 32nd Annu. Power Electronics Specialists Conf. (PESC), Vancouver, BC, Canada, Jun. 2001, vol. 2, pp. 799-804.

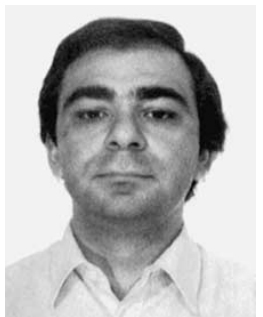

Fabio Giulii Capponi (M'96) received the M.S. and Ph.D. degrees in electrical engineering from the University of Rome "La Sapienza," Rome, Italy, in 1994 and 1998, respectively.

In 1996, he joined the Department of Electrical Engineering, University of Rome "La Sapienza," where he is an Assistant Professor. In 2003 and 2004, he was a Visiting Scholar at the Wisconsin Electrical Machines and Power Electronics Consortium (WEMPEC), University of Wisconsin, Madison. His research interests include permanent-magnet motor drives and digital control systems design for unconventional power converter topologies.

Dr. Giulii Capponi is a member of the IEEE Industry Applications, IEEE Industrial Electronics, IEEE Power Electronics, and IEEE Control Systems Societies.

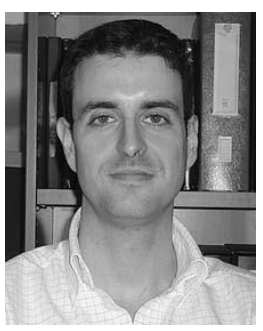

Giulio De Donato (S'05) was born in Cork, Ireland, in 1978. He received the M.S. degree in electrical engineering in 2003 from the University of Rome "La Sapienza," Rome, Italy, where he is currently working toward the Ph.D. degree in electrical engineering.

His research interests include advanced digital control of electrical drives, power electronics, and digital modulation techniques.

Mr. De Donato is a Registered Professional Engineer in Italy and is a member of the IEEE Industry Applications Society and IEEE Control Systems Society.

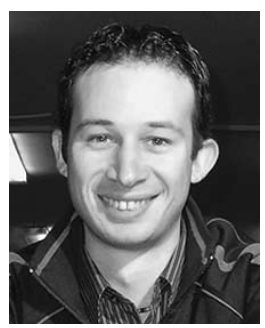

Luca Del Ferraro (S'05-M'06) received the M.S. and Ph.D. degrees in electrical engineering from the University of Rome "La Sapienza," Rome, Italy, in 2001 and 2005, respectively.

During 2005, he was a Visiting Scholar at the Wisconsin Electric Machines and Power Electronics Consortium (WEMPEC), University of Wisconsin, Madison. His research interests include unconventional electric machine design and power converter topologies for automotive applications.

Dr. Del Ferraro is a member of the IEEE Industry Applications Society.

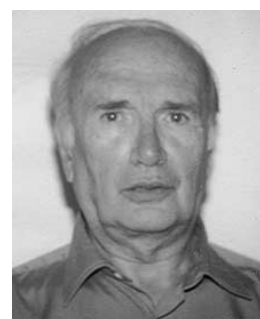

Onorato Honorati (M'73) received the degree in electrical engineering (cum laude) from the University of Turin, Turin, Italy, in 1964.

From 1971 to 1974, he was an Associate Professor at the University of L'Aquila, L'Aquila, Italy. From 1974 to 1980, he was an Associate Professor at the University of Rome "La Sapienza," Rome, Italy, where, since 1980, he has been a Full Professor of Electrical Machines in the Department of Electrical Engineering. His current research interests are the analysis and design of electrical machines and renewable energy generating systems.

Prof. Honorati is a member of the Italian Association of Electric and Electronics Engineers (AEI), the IEEE Power Engineering Society, and IEEE Industry Applications Society.

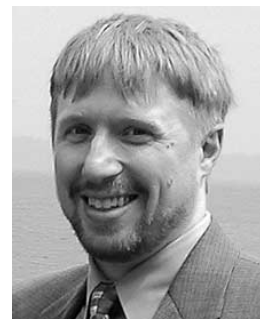

Michael C. Harke (S'98) received the B.S. and M.S. degrees in mechanical engineering in 1997 and 1999, respectively, from the University of Wisconsin, Madison, where he is currently working toward the $\mathrm{Ph} . \mathrm{D}$. degree in mechanical engineering.

The focus of his research is on sensorless control of permanent-magnet machines. His research interests include control systems, electric machines, and power electronics.

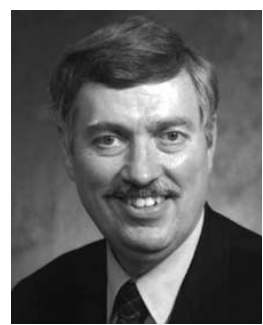

Robert D. Lorenz (S'83-M'84-SM'91-F'98) received the B.S., M.S., and Ph.D. degrees in mechanical engineering from the University of Wisconsin, Madison, and the M.B.A. degree from the University of Rochester, Rochester, NY.

Since 1984, he has been a member of the Faculty of the University of Wisconsin, Madison, where he is the Mead Witter Foundation Consolidated Papers Professor of Controls Engineering in both the Department of Mechanical Engineering and the Department of Electrical and Computer Engineering. He is a Co-Director of the Wisconsin Electric Machines and Power Electronics Consortium, which celebrated its 20th anniversary in 2001. It is the largest industrial research consortium on motor drives and power electronics in the world. He is also the Thrust Leader for Control and Sensor Integration in the Center for Power Electronic Systems, an NSF Engineering Research Center, which is a joint ERC with Virgina Polytechnic Institute, Rensselaer Polytechnic Institute, University of Puerto Rico-Mayaguez, and North Carolina A\&T. From 1972 to 1982, he was a member of the Research Staff at Gleason Works, Rochester, NY, working principally on high-performance drives and synchronized motion control. He was a Visiting Research Professor in the Electrical Drives Group of the Catholic University of Leuven, Leuven, Belgium, in the summer of 1989 and in the Power Electronics and Electrical Drives Institute of the Technical University of Aachen, Aachen, Germany, in the summers of 1987, 1991, 1995, 1997, and 1999 and was the SEW Eurodrive Guest Professor from September 1, 2000, until July 7, 2001. In 1969-1970, he did his Master thesis research in adaptive control of machine tools at the Technical University of Aachen. His current research interests include sensorless electromagnetic motor/actuator technologies, real-time signal processing and estimation techniques, precision multiaxis motion control, and alternating current/direct current $(\mathrm{ac} / \mathrm{dc})$ drive and high-precision machine control technologies. $\mathrm{He}$ has authored more than 170 published technical papers and is the holder of 21 patents, with three more pending.

Dr. Lorenz is a Registered Professional Engineer in the States of New York and Wisconsin. He is a member of the American Society of Mechanical Engineers, the Instrument Society of America, and the International Society for Optical Engineers. He is the IEEE Division II Director for 2005/2006, was the IEEE Industry Applications Society (IAS) President for 2001, a Distinguished Lecturer of the IEEE IAS for 2000/2001, the past Chair of the IAS Awards Department, the past Chairman of the IAS Industrial Drives Committee, and is a member of the IAS Industrial Drives Committee, Electrical Machines Committee, Industrial Power Converter Committee, and Industrial Automation and Control Committee. He is the immediate past Chair of the Periodical Committee and the current Chair of the Periodicals Review Committee for the IEEE Technical Activities Board. He is a member of the IEEE Sensor Council AdCom. He received the 2003 IEEE IAS Outstanding Achievement Award, which honors his outstanding contributions and technological developments in the application of electricity to industry. He has won 19 Prize Paper Awards. 